\title{
Progesterone modulates endothelium-dependent coronary vascular reactivity in SHR
}

\author{
Débora Tacon da Costa, Leticia Tinoco Gonçalves, Jéssyca Aparecida Soares Giesen $(\mathbb{D}$ and Roger Lyrio dos Santos \\ Department of Physiological Sciences, Health Sciences Center, Federal University of Espirito Santo, Vitoria, Espirito Santo, Brazil \\ Correspondence should be addressed to R L dos Santos: rogerlyrio@hotmail.com
}

\begin{abstract}
Although progesterone has the ability to promote dilation of vascular smooth muscle, its role in coronary circulation is still poorly characterized, especially in essential hypertension and in a model of endogenous deficiency of ovarian hormones.

Thus, this study evaluated the effect of progesterone treatment on endotheliumdependent coronary vascular reactivity in hypertensive (SHR) and ovariectomized rats. Adult SHR aged 8-10 weeks were divided into: SHAM, Ovariectomized (OVX) and Ovariectomized + treatment with $2 \mathrm{mg} / \mathrm{kg} /$ day of progesterone for 15 days (OVX-P4). Coronary vascular reactivity was investigated using the modified Langendorff method. After stabilization, baseline coronary perfusion pressure (CPP) was recorded and vascular reactivity to bradykinin ( $\mathrm{BK}, 0.1-1000 \mathrm{ng}$ ) were assessed before and after infusion, either individually or in combination, with $\mathrm{N}^{\omega}$-nitro-L-arginine methyl ester (L-NAME), indomethacin or clotrimazole. Scanning electron microscopy was used for qualitative analysis of the endothelium. OVX and OVX-P4 groups had a higher baseline CPP compared to that of the SHAM group. BK was able to promote vasodilation in all groups. However, relaxation to BK was less pronounced in the OVX group when compared to SHAM, with architecture loss and areas of cell atrophy having been observed. Progesterone treatment prevented this injury. Perfusion with L-NAME induced greater damage to the SHAM group, while the use of indomethacin led to a significant reduction in the vasodilator response to BK in the OVX-P4 group. Taken together, our results show that progesterone modulates endothelium-dependent coronary vasodilation in SHR ovariectomized, preventing damage caused by ovarian hormonal deficiency through a mechanism that involves prostanoid pathway.
\end{abstract}

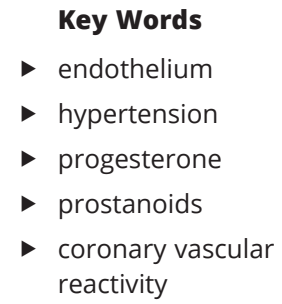

Journal of Molecular Endocrinology (2021) 66, 171-180

\section{Introduction}

There is evidence that progesterone (P4) plays a significant role in the vascular system, which may include the synthesis of endothelial mediators important for vascular homeostasis (Qiao et al. 2008). The endothelium, a monolayer of cells lining the internal face of blood vessels, is responsible for releasing vasodilator and vasoconstrictor factors that maintain vascular homeostasis (Kang
2014). The main relaxing factors include nitric oxide (NO), prostacyclin $\left(\mathrm{PGI}_{2}\right)$, and endothelium-dependent hyperpolarization $(\mathrm{EDH})$, while vasoconstrictor factors comprise endothelin-1, angiotensin II, thromboxanes, superoxide anion and hydrogen peroxide (Moncada et al. 1976, Ignarro et al. 1987, Palmer et al. 1987, Félétou \& Vanhoutte 1988, 2006b). 
P4 has the ability to promote relaxation in several vascular beds (Molinari et al. 2001, Minshall et al. 2002, Pang et al. 2015, Giesen et al. 2020) by stimulating the formation of the endothelial mediators NO (Selles et al. 2001, Chataigneau et al. 2004, Mendiberri et al. 2006, Cutini et al. 2014, Pang et al. 2015, Cunha et al. 2020) and $\mathrm{PGI}_{2}$ (Makila et al. 1982, Selles et al. 2002, Hermenegildo et al. 2005, Mendiberri et al. 2006), thus inducing protective effects that include preventing coronary heart disease, reducing systemic blood pressure and vasodilation in isolated arteries (Henderson et al. 1983, Cheng et al. 2002, Smyth et al. 2009, Chu et al. 2015).

The physiological effects of progesterone are modulated mainly by classical or genomic signals (Garg et al. 2017) through the nuclear progesterone receptor (PRn) (O'Malley \& Buller 1977). This is a slow mechanism of action (Thomas 2008) that involves the regulation of transcription and gene expression (Tsai \& Malley 1994, Jacobsen \& Horwitz 2012). On the other hand, P4 can also generate rapid hormonal effects without transcriptional activation, in a so-called non-classical or non-genomic signaling pathway (Garg et al. 2017). This type of response is mediated by membrane receptors (mPRs) (Zhu et al. 2003, Thomas 2008, Pang et al. 2015), with the connection between P4 and mPR occurring on the cell surface, which leads to the generation of second messengers in an agile way (Smith et al. 2008).

Some studies have shown that these receptors are expressed in vascular endothelial and muscle cells (Vázquez et al. 1999, Thomas \& Pang 2013). Furthermore, it has been demonstrated that acute administration of progesterone caused vasodilation in the coronary circulation, and that NO synthesis could be involved (Molinari et al. 2001). However, the mechanisms by which the release of mediators occurs remain uncertain. It has been suggested that progesterone stimulates NO production in human umbilical vein endothelial cells (HUVECs) via $\mathrm{mPR}$ and involves signaling through PI3K/Akt and MAP kinase (Pang et al. 2015). It has been also suggested that the increase in prostacyclin by $\mathrm{P} 4$ is related to PR-mediated mechanisms, probably involving increased expressions and activity of COX-1 and COX-2 (Hermenegildo et al. 2005).

Studies on the effects of progesterone and its relationship with endothelial function in hypertension remain scarce. Bearing in mind that hypertension is one of the main causes of cardiovascular disease, knowledge on the possible benefits related to progesterone treatment in this context becomes of paramount importance, both for understanding the mechanisms involved and for developing better forms of therapy for postmenopausal women. Therefore, the aim of this study was to evaluate the effects of progesterone treatment on endotheliumdependent coronary vascular reactivity in spontaneously hypertensive rats. Our hypothesis is that treatment with progesterone prevents the damage to endotheliumdependent vasodilation induced by gonadectomy in hypertensive rats.

\section{Materials and methods}

\section{Experimental animals}

The present study used adult female SHR (spontaneously hypertensive rats) between 10 and 12 weeks old, which were provided by the animal facility of the Health Sciences Center at the Federal University of Espirito Santo. Research protocols were approved by our local Ethics Committee for the Use of Animals under protocol no. $42 / 2018$. The animals were housed in groups under controlled temperature $\left(22-24^{\circ} \mathrm{C}\right)$ and humidity $(40-60 \%)$ conditions, with a $12 \mathrm{~h}$ light: $12 \mathrm{~h}$ darkness cycle and water and food ad libitum (standard diet for housed animals, Purina Labina, SP, Brazil). The animals were divided into three groups: SHAM, ovariectomized (OVX), OVX and treated with progesterone (OVX-P4).

\section{Ovariectomy}

Ovariectomy was performed under general anesthesia (i.p.) with ketamine $(70 \mathrm{mg} / \mathrm{kg})$ and xylazine $(10 \mathrm{mg} / \mathrm{kg})$. Subsequently, the animals were subjected to a bilateral incision in the skin followed by an incision in the muscular layer, opening the peritoneal cavity for posterior ligation of the uterine tube and removal of the ovaries. The tube was ligated with a suture and the ovaries removed. Muscle and skin were then sutured. After the surgery the animals received an antibiotic injection $(2.5 \%$ enrofloxacin, $0.1 \mathrm{~mL}$, i.m.). SHAM-operated rats underwent the same procedure, although the ovaries were exteriorized then placed back into the peritoneal cavity.

\section{Progesterone treatment}

Treatment with progesterone (Progesterone micronized Iberoquimica, $2 \mathrm{mg} / \mathrm{kg} / \mathrm{day}$, subcutaneous injections, diluted in $0.1 \mathrm{~mL}$ of sunflower oil) was performed for 15 days, with the first dose having been administered on the same day of ovariectomy to avoid low hormonal levels after surgery. The dose was set to mimic physiological 
conditions, as previously described (Bernardi et al. 2006, Cunha et al. 2020). Untreated groups received the same volume of vehicle (sunflower oil) only.

\section{Determination of the estrous cycle stage}

Estrous cycles were monitored through vaginal smears. Vaginal fluid was collected from each animal daily between 08:00 $\mathrm{h}$ and 09:00 $\mathrm{h}$ and vaginal epithelial cells examined under an optical microscope as previously described (Marcondes et al. 2002). The experimental protocols were performed on normal estrous cycles during the diestrus stage, in order to avoid any effects caused by hormonal variations in the different cycle stages.

\section{Non-invasive blood pressure assessment}

Systolic blood pressure (SBP) was assessed before starting of the treatment (day 0) and 1 day before of the vascular reactivity protocol (day 15) by the tail plethysmography method as previously described (Baldo et al. 2011).

The animals were heated in a holding chamber with a pneumatic cuff attached to the proximal region of the tail. A sphygmomanometer was inflated and deflated automatically and the SBP value was collected automatically using a device (IITC INC/Life Science, CA, USA) coupled to a computer. The temperature of the room was controlled between 35 and $37^{\circ} \mathrm{C}$ during the entire time that the animal remained in the equipment. The average of at least three records was obtained with a maximum difference of $10 \mathrm{mmHg}$, and the records associated with the influences caused by animal movements were discarded.

\section{Vascular reactivity studies in isolated hearts}

The vascular reactivity of the coronary bed was examined using the modified Langendorff method (Hugo Sachs Electronics, March-Hugstetten, Germany) as previously described (Debortoli etal. 2017). At the end of treatment, the animals were anesthetized with ketamine (70 $\mathrm{mg} / \mathrm{kg}$ i.p.) and xylazine (10 $\mathrm{mg} / \mathrm{kg}$ i.p.), the thoracic cavity exposed and the heart dissected from its connections, being immediately transferred to the perfusion apparatus.

The aorta was cannulated at the level of its curvature and continuously nourished with a modified Krebs solution $\left(\mathrm{NaCl}, 120 \mathrm{mmol} / \mathrm{L} ; \mathrm{CaCl}_{2} \mathrm{H}_{2} \mathrm{O}, 1.25 \mathrm{mmol} / \mathrm{L} ; \mathrm{KCl}\right.$, $5.4 \mathrm{mmol} / \mathrm{L} ; \mathrm{MgSO}_{4} \cdot 7 \mathrm{H}_{2} \mathrm{O}, 2.5 \mathrm{mmol} / \mathrm{L} ; \mathrm{NaH}_{2} \mathrm{PO}_{4} \cdot \mathrm{H}_{2} \mathrm{O}$, $2.0 \mathrm{mmol} / \mathrm{L} ; \mathrm{NaHCO}_{3}, 27.0 \mathrm{mmol} / \mathrm{L} ; \mathrm{Na}_{2} \mathrm{SO}_{4}, 1.2 \mathrm{mmol} / \mathrm{L}$; EDTA, $0.03 \mathrm{mmol} / \mathrm{L}$, and glucose $11.0 \mathrm{mmol} / \mathrm{L}$ ) continuously heated at $37^{\circ} \mathrm{C}$ and saturated with a carbogenic mixture $\left(95 \% \mathrm{O}_{2}\right.$ and $\left.5 \% \mathrm{CO}_{2}\right)$ to maintain the $\mathrm{pH}$ at 7.4. Baseline coronary perfusion pressure (CPP) was assessed using a pressure transducer connected to a digital data acquisition system, having been placed immediately near the aortic perfusion cannula, through which the coronary bed was perfused. Coronary flow was maintained constant at $10 \mathrm{~mL} / \mathrm{min}$ by means of a roller pump, which allowed changes in CPP to be directly related to changes in vascular resistance. The isovolumetric pressure of the left ventricle was controlled by means of a latex balloon inserted, while still empty, into the left ventricle (LV) through a steel cannula connected to a pressure transducer. Once inside the $\mathrm{LV}$, the balloon was pressurized with water by means of a glass syringe, in order to maintain an intraventricular diastolic pressure of $10 \mathrm{mmHg}$.

After $40 \mathrm{~min}$ of stabilization the baseline CPP was determined. Vascular response to bradykinin (BK) was evaluated by means of a dose-response curve (0.1-1000 ng) for BK (Sigma), obtained by bolus infusion before and after the infusion with individual or combined inhibitors of NOS ( ${ }^{\omega}{ }^{\omega}$-Nitro-L-arginine methyl ester, L-NAME, $100 \mu \mathrm{M}$ ), cyclooxygenase (indomethacin, $2.8 \mu \mathrm{M}$ ), or cytochrome P450 (clotrimazole, $0.75 \mu \mathrm{M}$ ).

The vasodilator response was expressed as the percentage of relaxation and calculated using the following equation:

$$
\Delta \%=100-\left(\frac{\mathrm{CPP}_{\text {after infusion }} \times 100}{\mathrm{CPP}_{\text {before infusion }}}\right)
$$

Rmax refers to the percentage of the maximum response induced by BK before and after inhibition with pharmacological agents. We used the average of relaxation percentages $(\Delta \%)$ of the last BK dose administered here.

\section{Scanning electron microscopy (SEM)}

Coronary arteries were collected, washed with PBS, opened longitudinally to expose the endothelial surface and fixed in Karnovsky solution (2.5\% glutaraldehyde, $2 \%$ paraformaldehyde, $0.1 \mathrm{M}$ cacodylate buffer, $\mathrm{pH}$ 7.2) for $24 \mathrm{~h}$. Afterwards, the arteries were post-fixed in 1\% osmium tetroxide and $3.8 \%$ potassium ferricyanide, being subsequently dehydrated in different concentrations of ethanol (30, 50, 70, 90, 100\%). Following the dehydration period, the arteries were processed at the critical point, being submitted to a $\mathrm{CO}_{2}$ drying process. Finally, a 10 $\mathrm{nm}$ gold layer was evaporated on the now dried tissue surface. Images were obtained using a scanning electron 
microscope. For each specimen, photomicrographs were randomly taken at 1500 magnification.

\section{Statistical analysis}

Data analysis was performed using GraphPad Prism 8 (GraphPad Software) and all data were expressed as mean \pm s.E.M. Outliers were detected using the GraphPad Prism ROUT test. Data normality was evaluated through the Shapiro-Wilk test. Following confirmation of data normality, CPP, SPB and weight values were analysed using one-way ANOVA and the vasodilator response to bradykinin (BK) was evaluated through two-way ANOVA. For comparisons between means, we used the Tukey's post hoc test with the significance level set at $P<0.05$.

\section{Results}

\section{Weight data}

Data on the weight of the animals employed here are presented in Tables 1 and 2. The animals were weighted on the days of ovariectomy (day 0) and sacrifice (day 15), and a similar increase in body weight was observed in all groups (Table 1). Regarding SBP (Table 1), we observed an increase related to age progression, but interventions performed in each group, such as ovariectomy and treatment with progesterone, did not affect the increase in SBP. As expected, ovariectomy promoted uterine atrophy in the OVX group, pointing to the effectiveness of the castration technique (Table 2), an outcome that could not be prevented by progesterone treatment. In order to verify the total composition of the fat mass, we added the values of intra-abdominal fats, which revealed that the OVX group had greater fat deposition compared to the other groups. Progesterone treatment seems to prevent the deposition of intra-abdominal fat, as treated animals presented similar weights to those of the SHAM group (Table 2).

Table 1 Body weight and systolic blood pressure values of studied groups.

\begin{tabular}{|c|c|c|c|}
\hline PARAMETER & SHAM & ovx & OVX-P4 \\
\hline $\mathrm{BW}^{1}$ (g) & $134 \pm 2$ & $137 \pm 3$ & $128 \pm 2$ \\
\hline $\mathrm{BW}^{2}(\mathrm{~g})$ & $147 \pm 2 *$ & $159 \pm 4^{*}$ & $153 \pm 3 *$ \\
\hline $\mathrm{SBP}^{1}(\mathrm{mmHg})$ & $155 \pm 2$ & $155 \pm 0.8$ & $158 \pm 2$ \\
\hline $\mathrm{SBP}^{2}(\mathrm{mmHg})$ & $165 \pm 1.9 *$ & $169 \pm 1.4^{*}$ & $170 \pm 2 *$ \\
\hline
\end{tabular}

Values were expressed as mean \pm S.E.M.. Statistical analyses were performed using one-way ANOVA and Tukey's post hoc test. ${ }^{*} P<0,05$ vs respective controls. SBP: $n=15$. BW: SHAM $(n=54)$; OVX $(n=53)$; OVX-P4 $(n=56)$. BW: body weight; SBP: systolic blood pressure. ${ }^{1}$ day 0; ${ }^{2}$ day 15.
Table 2 Weight of the uterus and intra-abdominal fats of the studied groups.

\begin{tabular}{|c|c|c|c|}
\hline & SHAM $(n=54)$ & $\operatorname{OVX}(n=53)$ & OVX-P4 $(n=56)$ \\
\hline$\sum$ Fats & $59 \pm 2.0$ & $66 \pm 2.0 * \#$ & $57 \pm 2.0$ \\
\hline MF & $43 \pm 2.0$ & $40 \pm 2.0$ & $39 \pm 1.0$ \\
\hline PrF & $6.5 \pm 0.5$ & $8.2 \pm 0.5^{*} \#$ & $6.6 \pm 0.4$ \\
\hline PF & $7.5 \pm 0.7$ & $8.3 \pm 0.6$ & $7.2 \pm 0.5$ \\
\hline RF & $4.9 \pm 0.5$ & $6.7 \pm 0.5^{*} \#$ & $5.2 \pm 0.3^{*}$ \\
\hline $\begin{array}{l}\text { Wet Uterus Úmido } \\
\qquad(n=23)\end{array}$ & $5.0 \pm 0.5$ & $2.0 \pm 0.3^{*}$ & $2.0 \pm 0.1 *$ \\
\hline Dry Uterus $(n=23)$ & $1.0 \pm 0.1$ & $0.5 \pm 0.07 *$ & $0.5 \pm 0.04 *$ \\
\hline
\end{tabular}

Values were expressed as mean \pm S.E.M. Statistical analysis was performed using one-way ANOVA and Tukey's post hoc. ${ }^{*} P<0.05$ vs Sham; $\# P<0.05$ vs OVX-P4.

$\mathrm{MF}$, mesenteric fat; PrF, perirenal fat; $\mathrm{PmF}$, parametrial fat; $\mathrm{RF}$, retoperitoneal fat; $\sum$, summation.

\section{Baseline CPP and coronary vascular reactivity}

Baseline CPP levels were significantly higher in the OVX (145 $\pm 1.7 \mathrm{mmHg}$ ) and OVX-P4 groups (OVX-P4: $145 \pm 2.3$ $\mathrm{mmHg})$ compared to the SHAM group $(130 \pm 3.8 \mathrm{mmHg})$ (Fig. 1).

We assessed vascular reactivity and endothelial functionality through dose-response relaxation curves with increasing concentrations of BK. We observed that, although the vasodilator response was present in all groups (Fig. 2), it was markedly less prominent in the OVX group $(\mathrm{SHAM}=10 \pm 1 \%$; OVX $=7 \pm 1 \%$; OVX-P $4=11 \pm 1 \%$ ). Thus, treatment with progesterone seems to prevent the reduction in relaxation induced by ovariectomy.

After the nonspecific inhibition of nitric oxide synthase with L-NAME (Fig. 3), the vasodilator response was found to be reduced in the SHAM and OVX-P4 groups $(\mathrm{SHAM}=5.8 \pm 0.9 \%$; OVX-P4 $=6 \pm 0.6 \%)$, whereas no change was observed in the OVX group (OVX $=8 \pm 2 \%)$.

The nonspecific inhibition of prostanoids with indomethacin (Fig. 4) led to impaired endothelial

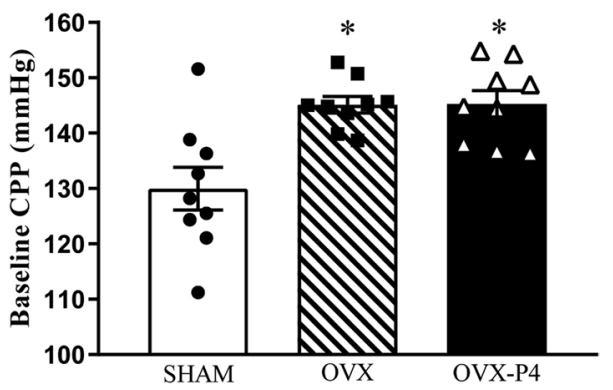

Figure 1

Baseline coronary perfusion pressure (CPP) in isolated hearts from SHR of SHAM $(n=9)$, OVX $(n=9)$ and OVX-P4 $(n=9)$ groups. Values were expressed as mean \pm s.E.M. Data were analyzed with one-way ANOVA followed by Tukey's post hoc test. ${ }^{*} P<0.05$ compared to SHAM. 


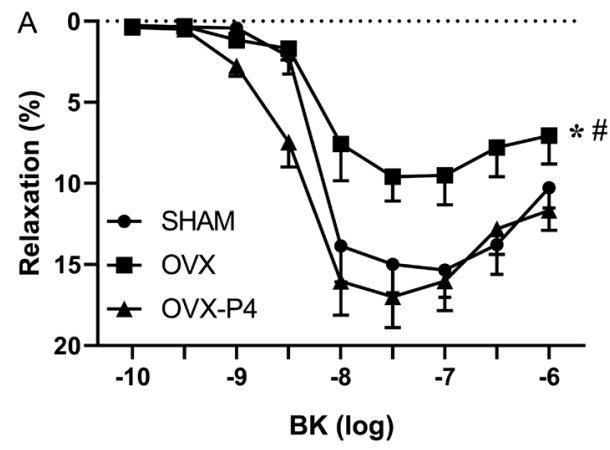

Figure 2

Vasodilator response to increasing concentrations of bradykinin (BK, 0.1-1000 ng) (A). Values were expressed as mean \pm S.E.M. Data were analyzed with two-way ANOVA and Tukey's post hoc test. ${ }^{*} P<0.05$ compared to SHAM, \#P<0.05 compared to OVX-P4.

vasodilation in the progesterone-treated group when compared to the basal BK curve (Fig. 2), while no such change was detected in the SHAM and OVX groups (SHAM $=10 \pm 1 \%$; OVX $=5 \pm 0.2 \%$; OVX-P $4=3 \pm 0.5 \%$ ). This outcome points to progesterone being able to modulate this particular pathway.

Upon the combined inhibition of the nitric oxide and prostanoid pathways (L-NAME plus Indomethacin) (Fig. 5), all groups had an impaired - although not completely abolished - vasodilator response $(\mathrm{SHAM}=3$ $\pm 0.4 \%$; OVX $=3.6 \pm 0.7 \%$; OVX-P4 $=3.8 \pm 0.7 \%$ ). These results hint at a possible participation of EDH. We investigated the role played by epoxyeicosatrienoic acids (EETs) in endothelium-dependent hyperpolarization through the simultaneous inhibition of the nitric oxide, prostanoids and EETs pathways (L-NAME, Indomethacin and Clotrimazole). That resulted in the reduction of the vasodilator response in all groups (Fig. 6), although it was not completely abolished in the OVX-P4 group $(\mathrm{SHAM}=0.7 \pm 0.2 \%$; OVX $=0.7 \pm 0.2 \%$; OVX-P4 $=2.3 \pm 0.5 \%$ ).

\section{Scanning electron microscopy (SEM)}

In order to confirm the results related to the endothelial dysfunction and screen for possible morphological changes, we performed a qualitative analysis of the intima layer of coronary arteries (left anterior descending and left septal) through scanning electron microscopy (s.E.M.) (Fig. 7). We found that the endothelial surface had a regular appearance in the SHAM group, with cells located along the longitudinal surface of the vessels. In the OVX group, the endothelium had an abnormal, contracted appearance, with a slight disorder of the intimal surface involving loss of the architecture and atypical disposition of endothelial cells, as well as areas of cellular atrophy - having been observed. In the OVX-P4 group, the endothelial layer was found to be similar to that of the SHAM group (Fig. 7).

\section{Discussion}

In the present study we found that progesterone was able to modulate endothelium-dependent coronary vasodilation in ovariectomized SHRs, as treatment with this steroid did prevent the damage caused by ovariectomy, with prostanoids appearing to play a significant role in this response.

First, although SBP remained unchanged - much like what had been already reported by previous studies (Pelzer et al. 2005, Dalpiaz et al. 2015) - we observed that ovariectomy led to an increase in baseline CPP that could not be reversed by treatment with progesterone. These results differ from those reported by a previous study carried out in normotensive animals, in which ovariectomy reduced CPP and treatment with progesterone was able to prevent this reduction (Cunha et al. 2020). That could be the result of sex hormones having different actions in
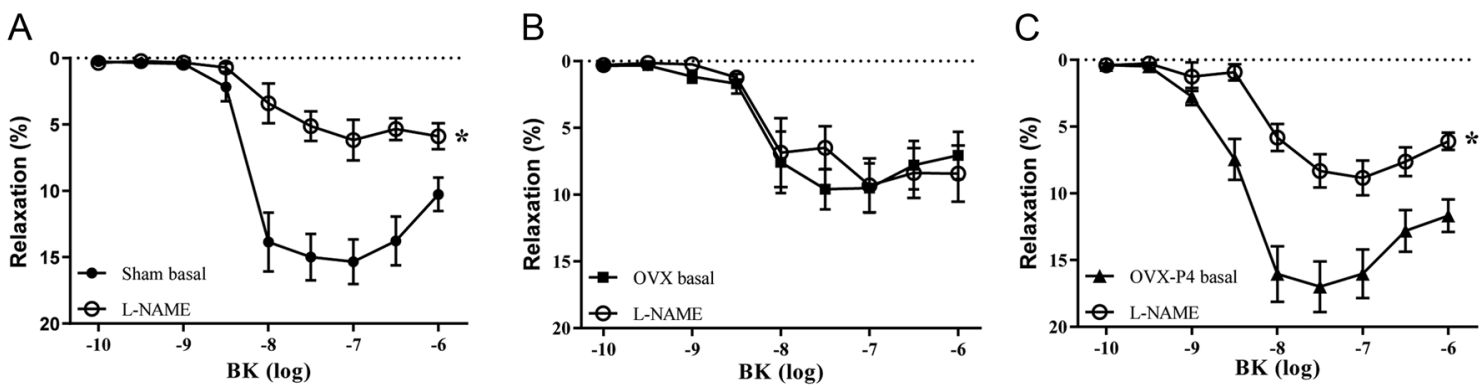

Figure 3

Vasodilator response to increasing concentrations of bradykinin (BK, 0.1-1000 ng) after inhibition with L-NAME in groups SHAM (A), OVX (B), OVX-P4 (C). Values were expressed as mean \pm S.E.M. Data were analyzed with two-way ANOVA and Tukey's post hoc test. * $P<0.05$ compared to the respective controls in the basal curves. 
A

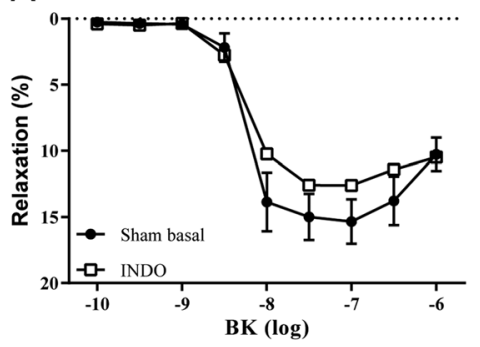

B

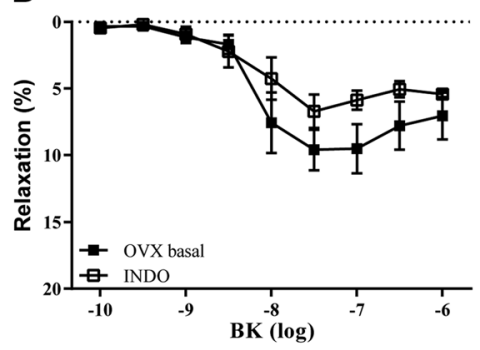

C

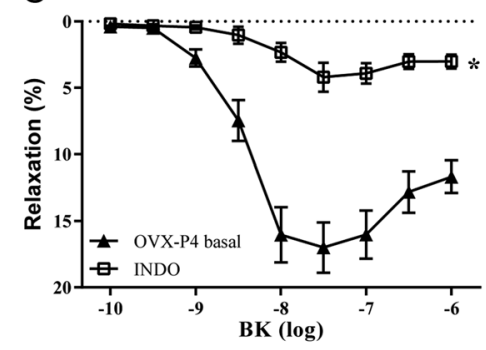

\section{Figure 4}

Vasodilator response to increasing concentrations of bradykinin (BK, 0.1-1000 ng) after inhibition with indomethacin in groups SHAM (A), OVX (B), OVX-P4 (C). Values were expressed as mean \pm S.E.M. Data were analyzed with two-way ANOVA and Tukey's post hoc test. * $P<0.05$ compared to the respective controls in the basal curves.

healthy and pathological conditions (Rossouw et al. 2002, Anderson et al. 2004, Cox et al. 2005, Manson et al. 2013, Meyer et al. 2016).

Although we did observe differences in baseline CPP, our main goal here was to evaluate the ability of progesterone in modulating endothelium-dependent vasodilation in ovariectomized hypertensive rats. In the present study, bradykinin - an endothelium-dependent vasodilator promoted relaxation in all groups studied, although much less so in the OVX group when compared to SHAM.

That was an expected outcome, for it has been well established that endothelial dysfunction can be the result of the hormonal deficiency caused by ovariectomy (Claudio et al. 2014, Borgo et al. 2016, Cheng et al. 2016). Endothelial dysfunction occurs when there is an imbalance in the release of vasoactive factors, with vasoconstrictor agents being released more than vasodilator factors (Félétou \& Vanhoutte 2006a, Vanhoutte 2009). In a previous study, we reported similar results in normotensive rats (Cunha et al. 2020), indicating that sex hormone deficiency is an important factor for the development of endothelial dysfunction.
Endothelial dysfunction caused by ovariectomy was confirmed through scanning electron microscopy (Fig. 7), which revealed loss of architecture and an atypical disposition of endothelial cells, although such damage was prevented by treatment with progesterone. The impairment in BK-induced vasodilation observed in the OVX-P4 group is also evidence that endothelial dysfunction took place.

We evaluated the participation of the nitric oxide pathway and observed that it appears to modulate BK-induced relaxation in the SHAM group, as a significant reduction in the vasodilator response could be detected after inhibition with L-NAME. In fact, Kelm et al. had already demonstrated that, regarding vascular reactivity, SHR display higher sensitivity to BK along with greater release of NO in the coronary circulation when compared to Wistar Kyoto animals. They suggested that this difference could be the result of a compensatory mechanism that aims at counteracting changes in vascular reactivity caused by arterial hypertension (Kelm et al. 1992).

Nevertheless, our data indicate that ovariectomy reduced the participation of $\mathrm{NO}$, without altering the
A

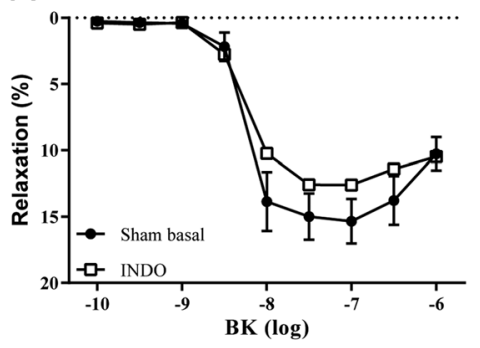

B

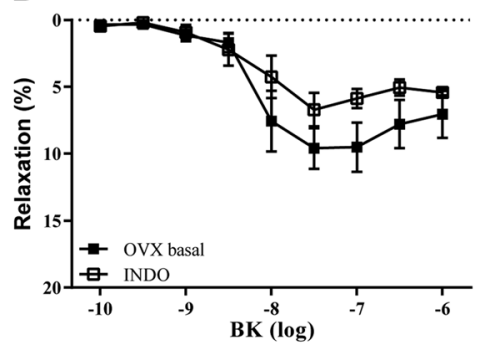

C

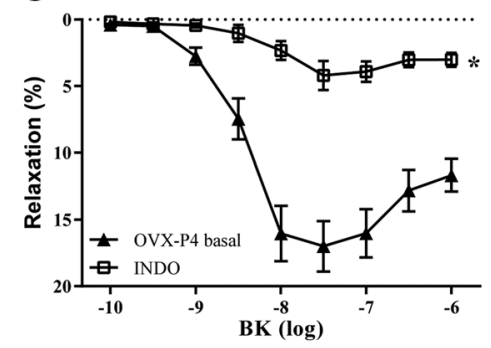

Figure 5

Vasodilator response to increasing concentrations of bradykinin (BK, 0.1-1000 ng) after inhibition with L-NAME plus indomethacin in groups SHAM (A), OVX (B), OVX-P4 (C). Values were expressed as mean \pm S.E.M. Data were analyzed with two-way and Tukey's post hoc test. * $P<0.05$ compared to the respective controls in the basal curves. 
A

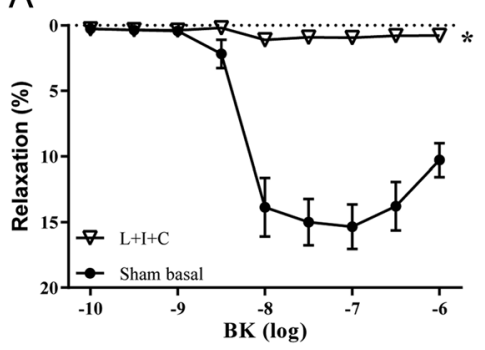

$\mathrm{B}$

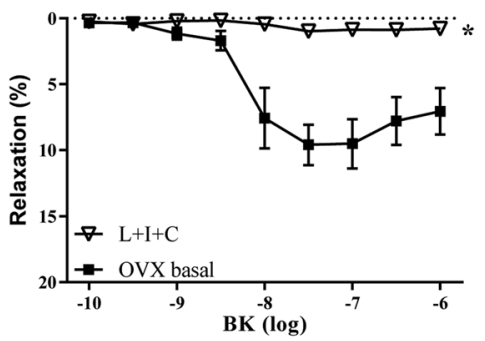

C

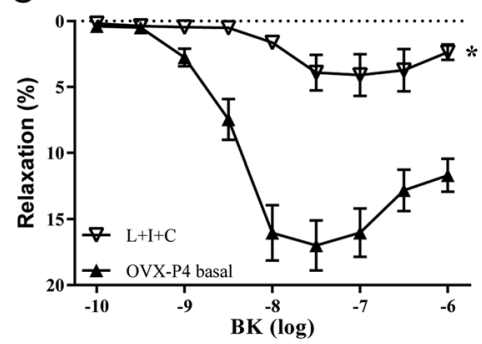

Figure 6

Vasodilator response to increasing concentrations of bradykinin (BK, 0.1-1000 ng) after inhibition with L-NAME, indomethacin and clotrimazole in groups SHAM (A), OVX (B), OVX-P4 (C). Values were expressed as mean \pm S.E.M. Data were analyzed with two-way ANOVA and Tukey's post hoc test. *P $<0.05$ compared to the respective controls in the basal curves.

vasodilator response, while treatment with progesterone restored its participation. We assume that progesterone was able to stimulate NO formation, as its ability to modulate the NO pathway has been previously demonstrated (Selles et al. 2001, 2002, Cutini et al. 2009, 2012, 2014, Cunha et al. 2020). Progesterone treatment has been shown to restore the vascular tone of mesenteric arteries in ovariectomized Wistar rats, an outcome attributed to the increase in NO synthesis (Chataigneau et al. 2004).

In addition to the participation of NO, our results indicate that treatment with progesterone stimulated the prostanoids pathway, with possible participation of prostacyclin in the relaxation induced by bradykinin. Progesterone's ability to stimulate the production of arachidonic acid-derived vasodilators, such as prostacyclin, has been demonstrated in human umbilical vein cell culture (Hermenegildo et al. 2005, Oviedo et al. 2011), and in the aorta of Wistar rats (Mendiberri et al. 2006). In addition to that, it decreases in thromboxane levels, a potent vasoconstrictor (Oviedo et al. 2011), and increases the activity of cyclooxygenases (Hermenegildo et al. 2005). The combined administration of L-NAME and indomethacin reduced the vasodilator response in the SHAM group. Although that was also observed when L-NAME was employed alone, the combined approach resulted in a much more pronounced effect, confirming that the metabolites of cyclooxygenase (COX) participate in the SHAM group only in the absence of NO. Interestingly, the opposite occurred in the OVX-P4 group, in which, although there was a reduction in the response upon combined inhibition, it was similar from that observed with indomethacin alone, suggesting that the prostanoid pathway plays an important role in BK-induced vasodilation.

When the $\mathrm{NO}$ and $\mathrm{PGI}_{2}$ pathways were individually inhibited in the OVX group the outcome was similar to that of the baseline curve for this group. However, the combined inhibition reduced the vasodilator response, suggesting the presence of EDH. We had already shown that EETs are strong candidates for the promotion of EDH in the coronary bed of hypertensive rats (Santos et al. 2010). Thus, we verified the participation of this endothelial pathway in BK-induced vasodilation with the combined inhibition of NOS, COX and CYP enzymes. We observed that the vasodilator response was abolished in
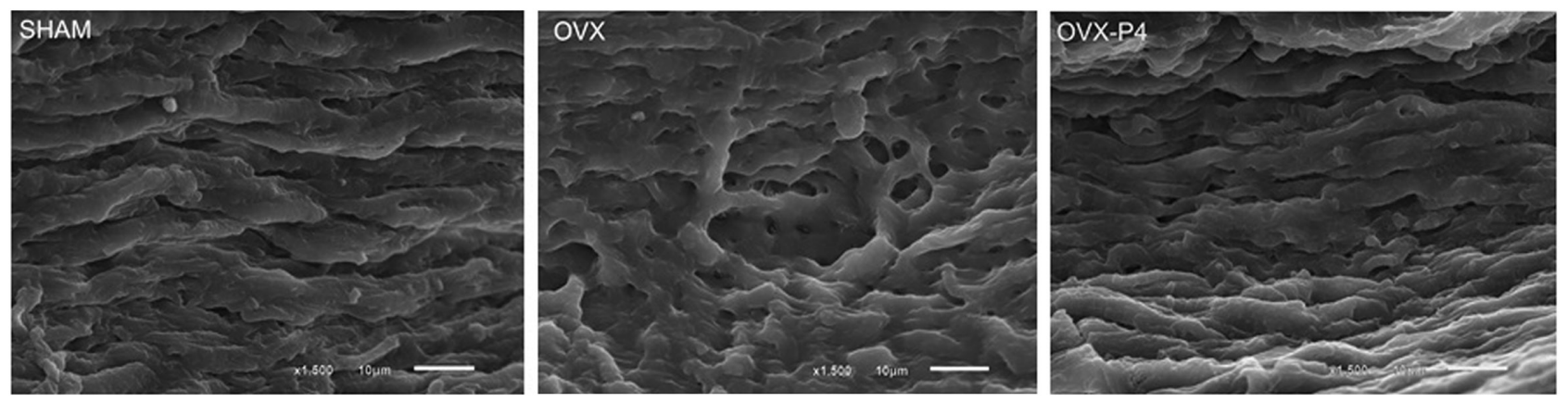

\section{Figure 7}

Scanning electron microscopy (SEM) images showing the endothelial surface of coronary arteries in groups SHAM, OVX and OVX-P4. Each image was obtained under $1500 \times$ magnification (bar $=10 \mu \mathrm{m})$.

https://jme.bioscientifica.com https://doi.org/10.1530/JME-20-0187
(C) 2021 Society for Endocrinology Published by Bioscientifica Ltd. Printed in Great Britain 
the SHAM and OVX groups, while, in the OVX-P4 group, relaxation was similar to that found upon combined inhibition of $\mathrm{NO}$ and $\mathrm{PGI}_{2}$, suggesting that a factor other than EETs could act on BK-induced vasodilation.

We believe that hydrogen peroxide is a possible candidate for the establishment of EDH in the OVX-P4 wgroup. It has been shown that $\mathrm{H}_{2} \mathrm{O}_{2}$ is an important regulator of coronary vascular tone (Yada et al. 2003), promoting EDH-type responses in several vascular beds (Matoba et al. 2000, 2003, Yada et al. 2003). In addition, the participation of $\mathrm{H}_{2} \mathrm{O}_{2}$ becomes prominent in pathological situations, when there is a reduction in the role played by NO (Miura et al. 2003, Schenkel et al. 2014, Shimokawa 2020).

The cardioprotective effects of progesterone have not yet been fully elucidated, mainly when hypertension and deficiency of sex hormones are associated. Our results provide evidence that progesterone plays a relevant role in the vascular system by promoting vasodilation of the coronary bed and stimulating the release of endothelial mediators important for vascular homeostasis. In addition, our study shows that treatment with progesterone was able to prevent endothelial dysfunction even in the presence of arterial hypertension and endogenous hormonal deficiency. Thus, treatment with progesterone could contribute to the maintenance of endothelial function by exerting vasoprotective effects, at least in coronary arteries.

In conclusion, the present study demonstrates that progesterone is capable of modulating endotheliumdependent vascular reactivity in coronary arteries. Our results revealed a predominant main route for each group studied here. NO was an important mediator for the SHAM group, whereas prostanoids were essential for relaxation in the OVX-P4 group. As to the OVX group, EETs were found to be paramount in promoting vasodilation. Despite this predominance, NO also contributed significantly to relaxation in the OVX-P4 group and EETs in the SHAM group.

The current study has limitations and areas of future study. Our study evaluated three classic pathways that promote endothelium-dependent vasodilation. However, this study has some limitations, including the fact that we used drugs that inhibit NOS and COX enzymes in a non-specific manner. In addition, only one type of EDH response was evaluated here. Also, although scanning electron microscopy (s.E.M.) technique did provide us with significant qualitative results, it could not directly measure endothelial damage. Several questions remain unanswered, for instance, what factors influence progesterone signaling through receptors? What is the involvement of TP and IP receptors in the observed prostacyclin response? What are the impacts of progesterone on the endogenous antioxidant defense mechanism? Does this response include changes in vascular levels of nitric oxide, superoxide anion, or hydrogen peroxide? Future studies need to focus on these issues to determine how progesterone impacts the modulation of perfusion pressure and vascular reactivity in coronary arteries.

\section{Declaration of interest}

The authors declare that there is no conflict of interest that could be perceived as prejudicing the impartiality of this commentary.

\section{Funding}

This work was supported by CAPES and FAPES (no. 85142409).

\section{Author contribution statement}

Débora Tacon da Costa, Jéssyca Aparecida Soares Giesen and Leticia Tinoco Gonçalves involved in conception and design of the study, or acquisition of data, or analysis and interpretation of data; drafting the article or revising it critically for important intellectual content; final approval of the version to be submitted. Roger Lyrio dos Santoscontributed in drafting the article or revising it critically for important intellectual content; final approval of the version to be submitted.

\section{References}

Anderson GL, Limacher M, Assaf AR, Bassford T, Beresford SA, Preto H, Bonds D, Brunner R, Brzyski R, Caan B, et al. 2004 Effects of conjugated equine estrogen in postmenopausal women with hysterectomy: the Women's Health Initiative randomized controlled trial. JAMA 291 1701-1712. (https://doi.org/10.1001/ jama.291.14.1701)

Baldo MP, Forechi L, Morra EAS, Zaniqueli D, Machado RC, Lunz W, Rodrigues SL \& Mill JG 2011 Long-term use of low-dose spironolactone in spontaneously hypertensive rats : effects on left ventricular hypertrophy and stiffness. Pharmacological Reports 63 975-982. (https://doi.org/10.1016/s1734-1140(11)70613-2)

Bernardi F, Pluchino N, Pieri M, Begliuomini S, Lenzi E, Puccetti S, Casarosa E, Luisi M \& Genazzani AR 2006 Progesterone and medroxyprogesterone acetate effects on central and peripheral allopregnanolone and beta-endorphin levels. Neuroendocrinology $\mathbf{8 3}$ 348-359. (https://doi.org/10.1159/000095400)

Borgo MV, Claudio ERG, Silva FB, Romero WG, Gouvea SA, Moysés MR, Santos RL, Almeida SA, Podratz PL, Graceli JB, et al. 2016 Hormonal therapy with estradiol and drospirenone improves endotheliumdependent vasodilation in the coronary bed of ovariectomized spontaneously hypertensive rats. Brazilian Journal of Medical and Biological Research 49 e4655. (https://doi.org/10.1590/1414431X20154655)

Chataigneau T, Zerr M, Chataigneau M, Hudlett F, Hirn C, Pernot F \& Schini-Kerth VB 2004 Chronic treatment with progesterone but not medroxyprogesterone acetate restores the endothelial control of vascular tone in the mesenteric artery of ovariectomized rats. 
Menopause 11 255-263. (https://doi.org/10.1097/01 GME.0000097847.95550.E3)

Cheng TL, Lin YY, Su CT, Hu CC \& Yang AL 2016 Improvement of acetylcholine-induced vasodilation by acute exercise in ovariectomized hypertensive rats. Chinese Journal of Physiology $\mathbf{5 9}$ 165-172. (https://doi.org/10.4077/CJP.2016.BAE387)

Cheng Y, Austin SC, Rocca B, Koller BH, Coffman TM, Grosser T, Lawson JA \& Fitzgerald GA 2002 Role of prostacyclin in the cardiovascular response to thromboxane A2. Science 296 539-541. (https://doi.org/10.1126/science.1068711)

Chu LY, Liou JY \& Wu KK 2015 Prostacyclin protects vascular integrity via PPAR/14-3-3 pathway. Prostaglandins and Other Lipid Mediators 118119 19-27. (https://doi.org/10.1016/j.prostaglandins.2015.04.006)

Claudio ERG, Endlich PW, Santos RL, Moysés MR, Bissoli NS, Gouvêa SA, Silva JF, Lemos VS \& Abreu GR 2014 Effects of chronic swimming training and oestrogen therapy on coronary vascular reactivity and expression of antioxidant enzymes in ovariectomized rats. PLOS ONE 8 e64806. (https://doi.org/10.1371/journal.pone.0064806)

Cox MW, Fu W, Chai H, Paladugu R, Lin PH, Lumsden AB, Yao Q \& Chen C 2005 Effects of progesterone and estrogen on endothelial dysfunction in porcine coronary arteries. Journal of Surgical Research 124 104-111. (https://doi.org/10.1016/j.jss.2004.09.003)

Cunha TRD, Giesen JAS, Rouver WN, Costa ED, Grando MD, Lemos VS, Bendhack LM \& Santos RLD 2020 Effects of progesterone treatment on endothelium-dependent coronary relaxation in ovariectomized rats. Life Sciences 247 117391. (https://doi.org/10.1016/j. lfs.2020.117391)

Cutini P, Sellés J \& Massheimer V 2009 Cross-talk between rapid and long term effects of progesterone on vascular tissue. Journal of Steroid Biochemistry and Molecular Biology 115 36-43. (https://doi. org/10.1016/j.jsbmb.2009.02.014)

Cutini PH, Campelo AE, Agriello E, Sandoval MJ, Rauschemberger MB \& Massheimer VL 2012 The role of sex steroids on cellular events involved in vascular disease. Journal of Steroid Biochemistry and Molecular Biology 132 322-330. (https://doi.org/10.1016/j. jsbmb.2012.08.001)

Cutini PH, Campelo AE \& Massheimer VL 2014 Differential regulation of endothelium behavior by progesterone and medroxyprogesterone acetate. Journal of Endocrinology 220 179-193. (https://doi. org/10.1530/JOE-13-0263)

Dalpiaz PLM, Lamas AZ, Caliman IF, Ribeiro RF, Abreu GR, Moyses MR, Andrade TU, Gouvea SA, Alves MF, Carmona AK, et al. 2015 Sex hormones promote opposite effects on ACE and ACE2 activity, hypertrophy and cardiac contractility in spontaneously hypertensive rats. PLOS ONE 10 e0127515. (https://doi.org/10.1371/journal. pone.0127515)

Debortoli AR, Rouver WDN, Delgado NTB, Mengal V, Claudio ERG, Pernomian L, Bendhack LM, Moysés MR \& Santos RLD 2017 GPER modulates tone and coronary vascular reactivity in male and female rats. Journal of Molecular Endocrinology 59 171-180. (https://doi. org/10.1530/JME-16-0117)

Félétou M \& Vanhoutte PM 1988 Endothelium-dependent hyperpolarization of canine coronary smooth muscle. British Journal of Pharmacology 93 515-524. (https://doi. org/10.1111/j.1476-5381.1988.tb10306.x)

Félétou M \& Vanhoutte PM 2006a Endothelial dysfunction: a multifaceted disorder (the Wiggers Award Lecture). American Journal of Physiology. Heart and Circulatory Physiology 291 H985-H1002. (https://doi.org/10.1152/ajpheart.00292.2006)

Félétou M \& Vanhoutte PM 2006b Endothelium-derived hyperpolarizing factor: where are we now? Arteriosclerosis, Thrombosis, and Vascular Biology 26 1215-1225. (https://doi.org/10.1161/01. ATV.0000217611.81085.c5)

Garg D, Man Ng SSM, Baig KM, Driggers P \& Segars J 2017 Progesteronemediated non-classical signaling. Trends in Endocrinology and Metabolism 28 656-668. (https://doi.org/10.1016/j.tem.2017.05.006)
Giesen JAS, Rouver WDN, Costa ED, Lemos VS \& Santos RL 2020 Sex differences in progesterone-induced relaxation in the coronary bed from normotensive rats. Journal of Molecular Endocrinology 64 91-102. (doi:10.1530/JME-19-0171)

Henderson KM, Willcox DL \& Bruce NW 1983 Effect of infusion of PGI2, 6-keto-PGF-1 $\alpha$ and PGF-2 $\alpha$ on luteal function in the pregnant rat. Journal of Reproduction and Fertility 69 11-16. (https://doi. org/10.1530/jrf.0.0690011)

Hermenegildo C, Oviedo PJ, García-Martínez MC, García-Pérez MA, Tarín JJ \& Cano A 2005 Progestogens stimulate prostacyclin production by human endothelial cells. Human Reproduction $\mathbf{2 0}$ 1554-1561. (https://doi.org/10.1093/humrep/deh803)

Ignarro LJ, Buga GM, Wood KS, Byrns RE \& Chaudhuri G 1987 Endothelium-derived relaxing factor produced and released from artery and vein is nitric oxide. Proceedings of the National Academy of Sciences of the United States of America 84 9265-9269. (https://doi. org/10.1073/pnas.84.24.9265)

Jacobsen BM \& Horwitz KB 2012 Progesterone receptors, their isoforms and progesterone regulated transcription. Molecular and Cellular Endocrinology 357 18-29. (https://doi.org/10.1016/j.mce.2011.09.016)

Kang KT 2014 Endothelium-derived relaxing factors of small resistance arteries in hypertension. Toxicological Research 30 141-148. (https:// doi.org/10.5487/TR.2014.30.3.141)

Kelm M, Feelisch M, Krebber T, Motz W \& Strauer BE 1992 The role of nitric oxide in the regulation of coronary vascular resistance in arterial hypertension: comparison of normotensive and spontaneously hypertensive rats. Journal of Cardiovascular Pharmacology 20 (Supplement 12) S183-S186. (https://doi. org/10.1097/00005344-199204002-00051)

Makila UM, Wahlberg L, Viinikka L \& Ylikorkala O 1982 Regulation of prostacyclin and thromboxane production by human umbilical vessels: the effect estradiol and progesterone in a superfusion model. Prostaglandins, Leukotrienes, and Medicine 8 115-124. (https://doi. org/10.1016/s0262-1746(82)80003-6)

Manson JE, Chlebowski RT, Sthefanick ML, Aragaki AK, Rossouw JE, Prentice RL, Anderson G, Howard BV, Thomson CA, LaCroix AZ, et al. 2013 The Women's Health Initiative hormone therapy trials: update and overview of health outcomes during the intervention and post-stopping. JAMA 310 1353-1368. (https://doi.org/10.1001/ jama.2013.278040)

Marcondes FK, Bianchi FJ \& Tanno AP 2002 Determination of the estrous cycle phases of rats: some helpful considerations. Brazilian Journal of Biology= Revista Brasleira de Biologia 62 609-614. (https:// doi.org/10.1590/s1519-69842002000400008)

Matoba T, Shimokawa H, Morikawa K, Kubota H, Kunihiro I, Urakamiharasawa L, Mukai Y, Hirakawa Y, Akaike T \& Takeshita A 2003 Electron spin resonance detection of hydrogen peroxide as an endothelium-derived hyperpolarizing factor in porcine coronary microvessels. Arteriosclerosis, Thrombosis, and Vascular Biology 23 1224-1230. (https://doi.org/10.1161/01.ATV.0000078601.79536.6C)

Matoba T, Shimokawa H, Nakashima M, Hirakawa Y, Mukai Y, Hirano K, Kanaide H \& Takeshita A 2000 Hydrogen peroxide is an endothelium-derived hyperpolarizing factor in mice. Journal of Clinical Investigation 106 1521-1530. (https://doi.org/10.1172/ JCI10506)

Mendiberri J, Rauschemberger MB, Selles J \& Massheimer V 2006 Involvement of phosphoinositide-3-kinase and phospholipase $\mathrm{C}$ transduction systems in the non-genomic action of progesterone in vascular tissue. International Journal of Biochemistry \& Cell Biology 38 288-296. (https://doi.org/10.1016/j.biocel.2005.09.012)

Meyer MR, Fredette NC, Daniel C, Sharma G, Amann K, Arterburn JB, Barton M \& Prossnitz ER 2016 Obligatory role for GPER in cardiovascular aging and disease. Science Signaling 9 ra105. (https:// doi.org/10.1126/scisignal.aag0240)

Minshall RD, Pavcnik D, Browne DL \& Hermsmeyer K 2002 Nongenomic vasodilator action of progesterone on primate coronary https://jme.bioscientifica.com

https://doi.org/10.1530/JME-20-0187 (c) 2021 Society for Endocrinology Published by Bioscientifica Ltd. Printed in Great Britain 
arteries. Journal of Applied Physiology 92 701-708. (https://doi. org/10.1152/japplphysiol.00689.2001)

Miura H, Bosnjak JJ, Ning G, Saito T, Miura M \& Gutterman DD 2003 Role for hydrogen peroxide in flow-induced dilation of human coronary arterioles. Circulation Research 92 e31-e40. (https://doi. org/10.1161/01.RES.0000054200.44505.AB)

Molinari C, Battaglia A, Grossini E, Mary DASG, Stoker JB, Surico N \& Vacca G, Fisiologia L, Mediche S, Avogadro OA, et al. 2001 The effect of progesterone on coronary blood flow in anaesthetized pigs. Experimental Physiology 86 101-108. (https://doi.org/10.1113/ eph8602076)

Moncada S, Gryglewski R, Bunting S \& Vane JR 1976 An enzyme isolated from arteries transforms prostaglandin endoperoxides to an unstable substance that inhibits platelet aggregation. Nature $\mathbf{2 6 3}$ 663-665. (https://doi.org/10.1038/263663a0)

O'Malley BW \& Buller RE 1977 Herman Beerman lecture. Mechanisms of steroid hormone action. Journal of Investigative Dermatology $\mathbf{6 8}$ 1-4. (https://doi.org/10.1111/1523-1747.ep12485116)

Oviedo PJ, Sobrino A, Novella S, Rius C, Laguna-Fernandez A, GarcíaPerez MA, Tarín JJ, Cano A \& Hermenegildo C 2011 Progestogens reduce thromboxane production by cultured human endothelial cells. Climacteric 14 41-48. (https://doi. org/10.3109/13697131003602496)

Palmer RMJ, Ferrige AG \& Moncada S 1987 Nitric oxide release accounts for the biological activity of endothelium-derived relaxing factor. Nature 327 524-526. (https://doi.org/10.1038/327524a0)

Pang Y, Dong J \& Thomas P 2015 Progesterone increases nitric oxide synthesis in human vascular endothelial cells through activation of membrane progesterone receptor- $\alpha$. American Journal of Physiology. Endocrinology and Metabolism 308 E899-E911. (https://doi. org/10.1152/ajpendo.00527.2014)

Pelzer T, Jazbutyte V, Hu K, Segerer S, Nahrendorf M, Nordbeck P, Bonz AW, Muck J, Fritzemeier KH, Hegele-Hartung C, et al. 2005 The estrogen receptor- $\alpha$ agonist $16 \alpha$-LE2 inhibits cardiac hypertrophy and improves hemodynamic function in estrogen-deficient spontaneously hypertensive rats. Cardiovascular Research 67 604-612. (https://doi.org/10.1016/j.cardiores.2005.04.035)

Qiao X, McConnell KR \& Khalil RA 2008 Sex steroids and vascular responses in hypertension and aging. Gender Medicine $\mathbf{5}$ (Supplement A) S46-S64. (https://doi.org/10.1016/j.genm.2008.03.006)

Rossouw JE, Anderson GL, Prentice RL, LaCroix AZ, Kooperberg C, Stefanick ML, Jackson RD, Beresford SAA, Howard BV, Johnson KC, et al. 2002 Risks and benefits of estrogen plus progestin in healthy postmenopausal women. Principal results from the Women's Health Initiative randomized controlled trial. JAMA 288 321-333. (https:// doi.org/10.1001/jama.288.3.321)

Santos RL, Marin EB, Gonçalves WLS, Bissoli NS, Abreu GR \& Moysés MR 2010 Sex differences in the coronary vasodilation induced by $17 \beta$-oestradiol in the isolated perfused heart from spontaneously hypertensive rats. Acta Physiologica 200 203-210. (https://doi.org/10.1111/j.1748-1716.2010.02140.x)

Schenkel PC, Fernandes RO, Viegas VU, Campos C, Fernandes TRG, Sander AS \& Belló-klein A 2014 Catalase influence in the regulation of coronary resistance by estrogen : joint action of nitric oxide and hydrogen peroxide. Oxidative Medicine and Cellular Longevity 20146 pages 159852. (https://doi.org/10.1155/2014/159852)

Selles J, Polini N, Alvarez C \& Massheimer V 2001 Progesterone and 17 -estradiol acutely stimulate nitric oxide synthase activity in rat aorta and inhibit platelet aggregation. Life Sciences 69 815-827. (https://doi.org/10.1016/S0024-3205(01)01174-2)

Selles J, Polini N, Alvarez C \& Massheimer V 2002 Nongenomic action of progesterone in rat aorta : role of nitric oxide and prostaglandins. Cellular Signalling 14 431-436. (https://doi.org/10.1016/s08986568(01)00265-0)

Shimokawa H 2020 Reactive oxygen species in cardiovascular health and disease : special references to nitric oxide, hydrogen peroxide, and Rho kinase. Journal of Clinical Biochemistry and Nutrition 66 83-91. (https://doi.org/10.3164/jcbn.19-119)

Smith JL, Kupchak BR, Garitaonandia I, Hoang LK, Andrew S, Regalla LM \& Lyons TJ 2008 Heterologous expression of human $\mathrm{mPR} \alpha, \operatorname{mPR} \beta$ and $\mathrm{mPR} \gamma$ in yeast confirms their ability to function as membrane progesterone receptors. Steroids 73 1160-1173. (https:// doi.org/10.1016/j.steroids.2008.05.003.Heterologous)

Smyth EM, Grosser T, Wang M, Yu Y \& Fitzgerald GA 2009 Prostanoids in health and disease. Journal of Lipid Research $\mathbf{5 0}$ (Supplement) S423-S428. (https://doi.org/10.1194/jlr.R800094-JLR200)

Thomas P 2008 Characteristics of membrane progestin receptor alpha $(\mathrm{mPR} \alpha)$ and progesterone membrane receptor component one (PGMRC1) and their roles in mediating rapid progestin actions. Frontiers in Neuroendocrinology 29 292-312. (https://doi.org/10.1016/j. yfrne.2008.01.001.Characteristics)

Thomas P \& Pang Y 2013 Protective actions of progesterone in the cardiovascular system : potential role of membrane progesterone receptors (mPRs) in mediating rapid effects. Steroids 78 583-588. (https://doi.org/10.1016/j.steroids.2013.01.003)

Tsai MJ \& Malley BWO 1994 Molecular mechanisms of action of steroid/thyroid receptor superfamily members. Annual Review of Biochemistry 63 451-486. (https://doi.org/10.1146/annurev. bi.63.070194.002315)

Vanhoutte PM 2009 Endothelial dysfunction: the first step toward coronary arteriosclerosis. Circulation Journal: Official Journal of the Japanese Circulation Society 73 595-601. (doi:10.1253/circj.cj-08-1169)

Vázquez F, Rodríguez-Manzaneque JC, Lydon JP, Edwards DP, O'Malley BW \& Iruela-Arispe ML 1999 Progesterone regulates proliferation of endothelial cells. Journal of Biological Chemistry $\mathbf{2 7 4}$ 2185-2192. (https://doi.org/10.1074/jbc.274.4.2185)

Yada T, Shimokawa H, Hiramatsu O, Kajita T, Shigeto F, Goto M, Ogasawara Y \& Kajiya F 2003 Hydrogen peroxide, an endogenous endothelium-derived hyperpolarizing factor, plays an important role in coronary autoregulation in vivo. Circulation 107 1040-1045. (https://doi.org/10.1161/01.CIR.0000050145.25589.65)

Zhu Y, Bond J \& Thomas P 2003 Identification, classification, and partial characterization of genes in humans and other vertebrates homologous to a fish membrane progestin receptor. Proceedings of the National Academy of Sciences of the United States of America $\mathbf{1 0 0}$ 2237-2242. (doi:10.1073/pnas.0436133100)

Received in final form 26 November 2020

Accepted 5 January 2021

Accepted Manuscript published online 8 January 2021 https://jme.bioscientifica.com

https://doi.org/10.1530/JME-20-0187 (c) 2021 Society for Endocrinology Published by Bioscientifica Ltd. Printed in Great Britain 